\title{
Study on maritime specialty students discipline
}

\author{
Peirong Ge , Yongxiang Li , Hongbing Qin
}

Marine college of Shandong jiaotong university, Weihai, Shandong,China

\begin{abstract}
Keywords: Maritime specialty, discipline, A disciplinary offence, Countermeasures
\end{abstract}
\begin{abstract}
Maritime transportation is an important basic industry, related to the national economic and social development of the global. At present, the international shipping market continues to move East, China is the largest maritime shipping power to change shipping played an important supporting role. In the process of training high-quality talents for the shipping industry, quality is very important, discipline, but also important elements in quality. Based on the status of China's airlines Tao type of students majoring in disciplines, introduces Chinese maritime specialty students discipline content, features, existing implementation mechanism, characteristics of maritime specialty students the meaning of discipline and explain. Maritime specialty students ' discipline and discipline are necessary.
\end{abstract}

\section{Introduction}

21 st century is the century of marine, marine transportation plays an important role in national economic development. Navigation class specialized student Navigator-the future, strict discipline should have two implications, one of which is as college students should obey the rules, the other is the future as the correct understanding and implementation of the Voyager crew discipline.

Crew is " wide, flow, dispersion" professional characteristics, also has risks, hardship, independent, international, national defense and other features. Cultivation of talents for the shipping industry, not just professional knowledge learning and skill training, should cultivate noble patriotism and a high degree of discipline. Visit numerous maritime case is not difficult to see, the human factor is a major cause of marine. Also mentioned in the rules, occurrence of accidents at sea are caused by human factors. This due to the negligence of the crew does not perform accurate and professional discipline and procedures resulting from the maritime account for a very high proportion. Therefore, strengthen the education of maritime specialty students ' discipline was needed for the construction of socialist spiritual civilization, is the needs of shipping safety, but also the need of the modern shipping industry.

Navigation College of General thought political education workers after years of research and practice, navigation class professional students discipline implementation and education made has must of effectiveness, training has large of shipping talent, they has firm of political direction, and strongly of patriotism spirit, and height of discipline sex and good of soldiers quality, and skilled of expertise, and solid of practice skills, and strong of language integrated using capacity, and better of security and environmental consciousness, and international competitiveness and hard of spirit,.

However, due to maritime specialty students ' quality and defect of our examination-oriented education in the past and some of the discord in our community, frequent breaches of school discipline in students majoring in navigation behavior. It makes us think, why students majoring in navigation violations more navigation class specialized in how we develop the features of University students ' violation of what kind of preventive measures to combat this phenomenon to solve the problems of ideological and political education workers in this series.

For navigation class professional students discipline problem and existing of implementation mechanism, author for some in-depth of research and discussion, proposed has reduced navigation class professional students disciplinary behavior of countermeasures, despite is superficial, and theoretical and actual operation sex are to be further of discussion, but hope this papers on navigation class professional students discipline can has must of help, on navigation class College of students workers provides useful of reference. 


\section{Overview of Maritime specialty students ' discipline}

Regulations and discipline is necessary to maintain normal social order constraints and guarantees, discipline is needed in building Socialist material civilization and spiritual civilization, and students must possess the moral. Maritime majors should learning, knowing and ignorant of the law, compliance, improve legal awareness, enhance the sense of discipline, to meet the demands of the Socialist market economy, become outstanding talents for the shipping of the State and society need.

Marxism believes that discipline is determined by the material condition of human society, it is based on certain historical conditions and social relations, and change with changes in historical conditions and social relations.

Discipline is the life and the formation of productive labor. Differentiation of human beings from the Animal Kingdom, to survive, must be engaged in productive activities. In the production activities, must pass some form of organization, to establish certain social relations. Starting from the ancient times, people living in a certain social organizations, in the form of a clan, tribe or family, the tissue harvesting plant or hunted animals, live on. Any kind of social organization, are required to have certain rules and systems, to reunion together, forming a powerful force, organization of production, and withstand harsh natural environment.

\section{A. Maritime specialty students ' concept of discipline}

Students majoring in navigation is a component of a number of University students in China, maritime specialty students discipline refers to train qualified talents for the shipping industry to ensure successful completion maritime specialty students and life in order, seamen's career-oriented features in ideology and politics, learning and daily life on board and internship requirements set by marine technology and marine engineering majors to comply with specifications.

Maritime specialty students ' discipline specific content including daily life system, the House Health Bill, daily study regulations, will highlight the discipline inspection regulations, inspections and regulations, the flag-raising ceremony on board practice Ordinance. Maritime specialty students ' discipline and college students ' discipline and the same part has its specific content. Especially military management in maritime specialty discipline at the University, is its special composition. Implementation of quasi-military management in maritime specialty students, making disciplined of college students majoring in navigation, with a high sense of discipline, obedience and mob style.

\section{B. Navigation class specialized characteristics of college students ' discipline}

Maritime specialty students ' discipline is mandatory, half military, foreign-related features.

1) mandatory maritime specialty students discipline. Mandatory, mainly in the maritime professional college students ' discipline to obey the premise by means of punishment. The premise of so-called disciplinary subject, meaning that any student has to be in accordance with the provisions of the discipline to do what or what not to do. Practice regulations on board ships operating regulations are very strict and clearly identified categories of personnel, student must operate in accordance with the strict regulations of the post, without fail, otherwise light will cause the damage of equipment and personnel, severe cases will result in a ship crash.

2) paramilitary. Maritime specialty students to practice para-military management, highlight discipline parade, inspection, the flag-raising ceremony was half a concrete expression of the military administration of the Ordinance, requires that students must implement and mob ... Maritime specialty students ' discipline management has formed a distinctive grade student management system, established a "column-group-Squadron-district" grade the Student Government.

3) foreign. Foreign refers to maritime specialty students ' practice on Board of Foreign Affairs discipline set out in the Bill. Ocean-going ships are mobile, the crew landed in foreign ports, on behalf of a State and, therefore, they are called "civilian diplomacy." Maritime specialty students in internship, to pay attention to personal appearance, keep clothes clean, should always pay attention to safeguarding national dignity, reputation, strictly abide by the Foreign Affairs discipline, guarding State secrets. 


\section{Maritime specialty students ' disciplinary enforcement mechanisms}

Discipline comes from years of college students majoring in navigation in China to set up RMS high industrial school boat section of the students specification. People's Republic of China was founded, and maritime education entered a new historical stage of development. To adapt to the requirements of growing a new generation of talents for the shipping industry, after years of exploration, maritime specialty students ' discipline has formed from the discipline of design, implementation, to the cognizance of discipline, punishment, school appeals of disciplinary enforcement mechanism with Chinese characteristics.

\section{Research on maritime specialty students ' disciplinary and cause analysis}

Because the navigation class colleges and universities to implement strict management, led to instructors from the school teacher, attaches great importance to students ' ideological and political education work for student discipline issues is highly valued. Therefore, the mainstream of maritime specialty students disciplined is positive, healthy and upward. Maritime specialty students discipline and mainstream at the same time, you should see part of the student's performance is not satisfactory, violations have occurred on campus, and even some violations have reached extreme proportions. In-depth analysis of student misconduct, develop preventive measures, has become a big topic of student management and education.

Enter years later, rapid social transformation, economic knife everywhere, market operation law and order is not perfect, the old morality, a clear tendency to utilitarianism, material is no longer have nothing, poor in spirit. The new "useless" rise, hot business, sea fever caught on. Students majoring in navigation in the face of this turmoil and social trends, will certainly be affected, discipline has drastically increased. After 1989, due to "the student movement" reasons, and strengthening the management of students in schools, and strict in all, student disciplinary process more stringent, the number and more. In the years that followed, discipline wandering on the volume is kept low. After enrollment, maritime specialty students ' disciplinary offence again showed a rise trend ... Navigation class professional students number of increased must will caused disciplinary number of rose, but not denied of is, with university education by "elite education" to "civilians education" of development, navigation class professional students also appeared has good buckwheat not align, and genuine of situation, so disciplinary number continued rose, in 2004, and 2005 appeared peak, which must has school strengthening management, and strictly running of components, but must consider of spread enrollment zhihou students students quality declined of factors.

Marine major changes in the number of University students ' violation of both objective factors, such as changes in socio-economic and moral changes, changes in students qualities and other reasons, but also contain subjective factors, such as school management and will cause the student discipline number of ups and downs, in a year such as strict management, discipline, will naturally be reduced in the following years. Maritime specialty students between the ages most $\bullet$. Their age is a peak physiological and psychological development, and young people psychologically, "weaning period", on the one hand, and awareness of independence, self-awareness and participation, all kinds of things has its own analysis and understanding of the other hand, because the young, social experience and knowledge, often prone to ideological one-sidedness not (behavioral extremes. Impulsive young students of this age, emotionally unstable and tended to the Poles, sometimes exciting, sometimes negative, in a "stormy" emotions. Young students, especially irrational emotional performance. High density contacts between the navigation class specialized student will produce intense interaction, while under the control of emotions, produces so-called "tunnelling", resulting in a ' assimilation of ideas and emotions the will of the State, and by implication, conformity, imitation, infection and other ways. When individual violations occur, might eventually make many students follow. 


\section{Reducing maritime specialty students ' disciplinary measures}

To consciously abide by discipline, is essential to maritime specialty students ' future success. Quality of Dalian Maritime University graduates tracing investigation reports show that shipping company, maritime safety administration, port company 81-85 of Dalian Maritime University graduates the best quality work best, and ideological and political quality is highest. This coincides with the results of our survey, 81-85 students fewer violations. Based on the characteristics of students majoring in navigation and shipping personnel training goal, reducing maritime specialty students ' disciplinary, the development of preventive measures has become navigation class specialized teachers and political instructor of a top priority. Through the analysis of maritime specialty students ' disciplinary reasons, I think it should be from the students themselves, education and research on social environment and other aspects.

\section{A. Improve the quality of students majoring in navigation is the key to reducing violations}

Marxism holds that the external factors are changing the conditions, internal factors are changing according to external work through internal. Promote the quality of college students majoring in navigation as we discipline a priority.

B. Reforming disciplinary enforcement mechanisms with legal concepts and procedures to implement discipline management

Chinese maritime specialty students disciplinary enforcement mechanisms have been implemented for more than 50 years, formed a development, implementation of the disciplinary regulations to discipline found, penalties, complaints, such as a complete discipline in schools implementation mechanisms effectively to education management of students majoring in navigation. But we have to see the implementation mechanism's biggest drawback is that all operations are concentrated in one sector-Student Affairs Office.

C. Updating education concept, to optimize educational resources, and the environment

Education matters to us what kind of shipping talents, the fundamental problem of how to cultivate the students majoring in navigation. Campus is the main places of maritime specialty students ' learning and living. University students ' violation of navigational major events are happening on campus.

D. Create a navigation class specialized student grow up healthy and harmonious social environment

Maritime specialty students ' disciplinary problems is affected by a variety of factors. Reduce violations of college students majoring in navigation is a complex project, require participation and collaboration from a social perspective, and actively create a navigation class specialized student grow up healthy social environment.

\section{References}

[1]Wu Zhaolin. maritime education. the reform and development of ... Dalian Maritime University Press, 2003

[2] Wu Yuankai. world-class research on student management in maritime institutions of higher and more. study on maritime education and research, 2009

[3]Zhaopian Wang. do the navigation class specialized student's ideological and political work should pay attention to several issues. maritime education and research, 2010

[4] Hu Ya e. maritime specialty students ' education and career orientation guide. maritime education studies 2011. 
[5]Dong Haitao, Xi Yongtao, Zheng Hongyang. investigation and analysis on maritime specialty students ' psychological qualities. maritime education and research, 2011

[6] Bryan Ford, Pyda Srisuresh, and Dan Kegel. Peer-to-Peer Communication Across Network Address Translators. In USENIX Annual Technical Conference, Anaheim, CA, April, 2005.

[7] Rosenberg J. Schulzrinne H.Camarillo G.Johnston.A.Peterson , J.Sparks , and E.Schooler. SIP:Session Initiation Protocol. RFC 3261, June 2002. 